\title{
Isolation, Phenotypic Characterization, and Phylogenetic Position of a Novel, Facultatively Autotrophic, Moderately Thermophilic Bacterium, Thiobacillus thermosulfatus sp. nov.
}

\author{
FRÉDÉRIC SHOONER, ${ }^{1}$ JEAN BOUSQUET, ${ }^{2}$ AND RAJESHWAR D. TYAGI ${ }^{1 *}$ \\ Institut National de la Recherche Scientifique (INRS-Eau), Université du Québec, Sainte-Foy, Québec G1V 4C7, ${ }^{1}$ \\ and Centre de Recherche en Biologie Forestière, Université Laval, Sainte-Foy,
}

Québec G1K 7P4, ${ }^{2}$ Canada

\begin{abstract}
Thiobacillus thermosulfatus ATCC $51520^{\mathrm{T}}$ ( $\mathrm{T}=$ type strain) was isolated from sewage sludge samples enriched with elemental sulfur. The cells of this organism were gram negative, rod shaped, motile, facultatively autotrophic, and strictly aerobic and contained polyphosphate inclusions and polyhedral bodies. During growth on thiosulfate, the following intermediates were produced: tetrathionate, trithionate, and sulfate, and the pH was lowered from neutrality to around 2.5. Autotrophic growth was observed at pH values between 4.3 and 7.8 and at temperatures of 34 to $65^{\circ} \mathrm{C}$; optimum growth occurred at $\mathrm{pH} 5.2$ to 5.6 and 50 to $52.5^{\circ} \mathrm{C}$. Ubiquinone Q8 was present in the respiratory chain. The DNA contained $61 \pm 1 \mathrm{~mol} \% \mathrm{G}+\mathrm{C}$. No denitrification was observed under autotrophic and heterotrophic conditions. The cells produced a glycocalyx during growth in the presence of $S^{0}$. As determined by a $16 \mathrm{~S}$ rRA gene sequence analysis, $T$. thermosulfatus is a distinct species that belongs to the beta subdivision of the Proteobacteria and is closely related phylogenetically to Thiobacillus perometabolis. The GenBank accession number for the complete 16S rRNA gene sequence of $T$. thermosulfatus is $\mathrm{U} 27839$.
\end{abstract}

According to Kelly and Harrison (17) in Bergey's Manual of Systematic Bacteriology, the only criterion for grouping all of the Thiobacillus species in one genus is that all of these organisms are rod-shaped eubacteria that obtain energy for autotrophic growth from oxidizing inorganic sulfur-containing substrates. Consequently, this genus comprises species that have different $\mathrm{pH}$, temperature, and nutrient requirements. In fact, it includes organisms that are acidophilic, organisms that are neutrophilic, organisms that are thermophilic, denitrifiers, and facultative heterotrophs (19). When temperature requirements are considered, the following three Thiobacillus species are recognized as moderately thermophilic organisms: Thiobacillus tepidarius, Thiobacillus aquaesulis, and Thiobacillus caldus (3335). A Thiobacillus-like moderately thermophilic bacterium was also partially characterized by Williams and Hoare (32).

The great phenotypic diversity of the thiobacilli is supported by the results of genetic analyses. The first phylogenetic study of sulfur- and iron-oxidizing eubacteria placed members of the genus Thiobacillus in three of the four subdivisions of the Proteobacteria $(21,27)$. A phylogenetic analysis of $16 \mathrm{~S}$ rRNA gene sequences revealed that most members of the genus Thiobacillus belonged to the beta subdivision, but some strains were more closely related to other genera that are not iron or sulfur oxidizers (21). In fact, this study revealed that Thiobacillus acidophilus and Thiobacillus versutus were members of the alpha subdivision. Moreover, Thiobacillus acidophilus was closely linked to the genus Acidiphilium, suggesting that this organism should not be included in the genus Thiobacillus. The species Thiobacillus versutus and two other hydrothermal vent isolates were described as members of a new genus, and Thiobacillus ferrooxidans $\mathrm{M}-1$ and Thiobacillus thyasiris were classified as members of the gamma subdivision. Recently, Thiobacillus versutus and Thiobacillus thyasiris have been reclassified

\footnotetext{
* Corresponding author. Mailing address: Institut National de la Recherche Scientifique (INRS-Eau), Université du Québec, 2700 rue Einstein, C.P. 7500, Sainte-Foy, Québec G1V 4C7, Canada.
}

as Paracoccus versutus (13) and Thiomicrospira thyasirae, respectively $(9,36)$. These two taxonomic reclassifications have clarified the phylogenetic cohesion of the genus Thiobacillus, because almost all of the Thiobacillus species now belong to the beta subdivision of the Proteobacteria. The description of additional species should help define the phenotypic and phylogenetic limits of the genus Thiobacillus.

During the development phase of a new bioleaching technology, a bacterium that was able to oxidize elemental sulfur under thermophilic conditions was isolated from municipal wastewater treatment plant sludge samples $(24,25)$. In this paper we describe the isolation and the genotypic and phenotypic characteristics of this new thermophilic colorless sulfur bacterium, Thiobacillus thermosulfatus sp. nov.

\section{MATERIALS AND METHODS}

Isolation and cultivation of Thiobacillus thermosulfatus. Sludge samples obtained from municipal wastewater treatment plants were amended with $0.5 \%$ (wt/vol) tyndallized $\mathrm{S}^{0}$ powder and incubated in shaking water bath at $53^{\circ} \mathrm{C}$. Samples were removed aseptically daily to measure the decrease in $\mathrm{pH}$. Aliquots were transferred into medium A, which contained (per liter) $2.04 \mathrm{~g}$ of $\mathrm{KH}_{2} \mathrm{PO}_{4}$, $0.2 \mathrm{~g}$ of $\left(\mathrm{NH}_{4}\right)_{2} \mathrm{SO}_{4}, 0.2 \mathrm{~g}$ of $\mathrm{CaCl}_{2} \cdot 2 \mathrm{H}_{2} \mathrm{O}, 0.5 \mathrm{~g}$ of $\mathrm{MgSO}_{4} \cdot 7 \mathrm{H}_{2} \mathrm{O}$, and $0.02 \mathrm{~g}$ of bromophenol blue ( $\mathrm{pH}$ adjusted to 6.0 ), and $\mathrm{S}^{0}$ powder was added. After a few transfers, the $\mathrm{S}^{0}$ was replaced by $20 \mathrm{mM}$ sodium thiosulfate. Typically, the $\mathrm{pH}$ decreased from 6.0 to 2.3 to 2.5 in less than $24 \mathrm{~h}$. Serial dilutions were spread onto medium A supplemented with $20 \mathrm{mM}$ thiosulfate and $0.6 \%$ (wt/vol) Gelrite (22), and the preparations were incubated at $50^{\circ} \mathrm{C}$ for 2 days. Elimination of heterotrophic sporulated bacteria was verified throughout the isolation process on medium $\mathrm{H}$ (which contained $1.0 \mathrm{~g}$ of glucose per liter, $5.0 \mathrm{~g}$ of tryptone per liter, $2.5 \mathrm{~g}$ of yeast extract per liter, $0.6 \%$ Gelrite, and $0.57 \mathrm{~g}$ of $\mathrm{CaCl}_{2} \cdot 2 \mathrm{H}_{2} \mathrm{O}$ per liter) since growth of Thiobacillus thermosulfatus was never observed on this medium. Because all of the strains which we isolated were identical in terms of the rate of $\mathrm{pH}$ decrease, the minimum $\mathrm{pH}$ attained, and colonial and cellular morphology, one isolate was chosen arbitrarily for further characterization.

Determination of $\mathbf{p H}$ and temperature for growth. Experiments to determine the $\mathrm{pH}$ and temperature for growth were performed by using medium A supplemented with $20 \mathrm{mM}$ thiosulfate. The $\mathrm{pH}$ was automatically controlled with a $\mathrm{pH}$ controller (Horizon Ecology $\mathrm{Co}$.). Growth was monitored by measuring the optical density at $400 \mathrm{~nm}$ by using a $30-\mathrm{ml}$ cuvette with $10-\mathrm{cm}$ optical path. The specific growth rate constant $(k)$ was determined from the expression $k=\ln 2 /\left(t_{2}\right.$

$\left.-t_{1}\right)$, where $\left(t_{2}-t_{1}\right)$ was the time interval required for the bacterial count to double during the exponential growth phase. 
TABLE 1. Levels of similarity for Thiobacillus $16 \mathrm{~S}$ rRNA gene sequences used for phylogenetic analyses ${ }^{a}$

\begin{tabular}{|c|c|c|c|c|c|c|c|c|c|c|c|c|c|c|c|}
\hline \multirow[b]{2}{*}{ Organism } & \multirow[b]{2}{*}{$\begin{array}{l}\text { Subdivision of } \\
\text { Proteobacteria }^{b}\end{array}$} & \multicolumn{14}{|c|}{$\%$ Sequence similarity } \\
\hline & & 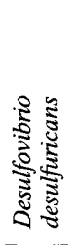 & 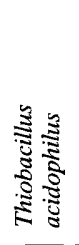 & 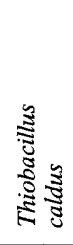 & 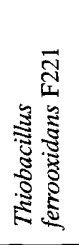 & 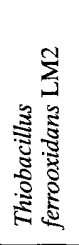 & 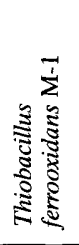 & 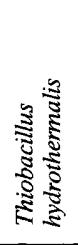 & 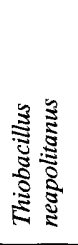 & 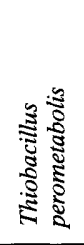 & 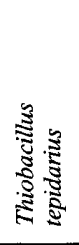 & 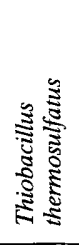 & 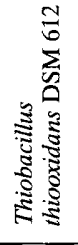 & 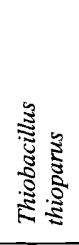 & 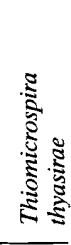 \\
\hline Desulfovibrio desulfuricans ${ }^{c}$ & Delta & & & & & & & & & & & & & & \\
\hline Thiobacillus acidophilus & Alpha & 74.4 & & & & & & & & & & & & & \\
\hline Thiobacillus caldus & $?$ & 76.9 & 81.7 & & & & & & & & & & & & \\
\hline $\begin{array}{l}\text { Thiobacillus ferrooxidans } \\
\text { F221 }\end{array}$ & Beta & 77.7 & 82.0 & 97.0 & & & & & & & & & & & \\
\hline $\begin{array}{l}\text { Thiobacillus ferrooxidans } \\
\text { LM2 }\end{array}$ & Beta & 75.7 & 81.0 & 98.7 & 96.9 & & & & & & & & & & \\
\hline $\begin{array}{l}\text { Thiobacillus ferrooxidans } \\
\text { M-1 }\end{array}$ & Gamma & 76.6 & 82.5 & 85.4 & 86.1 & 85.1 & & & & & & & & & \\
\hline Thiobacillus hydrothermalis & ? & 73.6 & 81.0 & 83.1 & 81.9 & 81.5 & 84.0 & & & & & & & & \\
\hline Thiobacillus neapolitanus & Beta & 77.3 & 82.9 & 83.7 & 85.4 & 82.9 & 87.5 & 91.8 & & & & & & & \\
\hline Thiobacillus perometabolis & Beta & 72.5 & 78.6 & 79.7 & 80.1 & 79.6 & 86.0 & 83.2 & 85.4 & & & & & & \\
\hline Thiobacillus tepidarius & Beta & 75.4 & 80.0 & 90.8 & 90.8 & 91.0 & 85.8 & 82.7 & 84.2 & 81.0 & & & & & \\
\hline Thiobacillus thermosulfatus & $?$ & 73.8 & 77.0 & 80.2 & 79.7 & 78.6 & 84.8 & 82.7 & 83.6 & $96.5^{e}$ & 80.9 & & & & \\
\hline $\begin{array}{l}\text { Thiobacillus thiooxidans } \\
\text { DSM } 612\end{array}$ & Beta & 77.9 & 82.2 & 96.9 & 98.0 & 96.1 & 86.4 & 81.9 & 84.4 & 81.0 & 90.4 & 80.1 & & & \\
\hline Thiobacillus thioparus & Beta & 73.6 & 77.3 & 80.9 & 81.1 & 79.5 & 84.7 & 84.1 & 85.2 & 87.1 & 82.0 & 85.7 & 80.9 & & \\
\hline Thiomicrospira thyasiraef & ? & 71.5 & 73.6 & 76.2 & 77.5 & 74.9 & 84.2 & 80.0 & 83.8 & 78.5 & 74.6 & 77.8 & 77.0 & 79.9 & \\
\hline Paracoccus versutus ${ }^{g}$ & Alpha & 73.3 & 81.2 & 75.2 & 75.2 & 74.5 & 80.6 & 75.8 & 78.2 & 76.6 & 77.8 & 76.1 & 76.2 & 76.6 & 72.2 \\
\hline
\end{tabular}

${ }^{a}$ Levels of similarity were calculated by excluding insertions and deletions and were based on 850 nucleotide positions (see Materials and Methods).

Data from reference 21 .

${ }^{c}$ This organism was used as an outgroup in phylogenetic analyses.

${ }^{d}$ This strain is the type strain of a group composed of closely related isolates ATCC 19377, ATCC 19859, ATCC 23270, B-53, IFO 14245, and IFO 14262 (Fig. 4).

${ }^{e}$ The level of similarity was $95.4 \%$ when all of the available sites were included in a pairwise comparison (see Results).

${ }^{f}$ Previously named Thiobacillus thyasiris (36).

g Previously named Thiobacillus versutus (13).

Growth on sulfur compounds and organic compounds. Growth experiments were performed at $50^{\circ} \mathrm{C}$ by using medium A supplemented with thiosulfate ( 20 $\mathrm{mM})$, tetrathionate $(10 \mathrm{mM})$, thiocyanate $(5,17$, and $85 \mathrm{mM}), \mathrm{S}^{0}(0.5 \%)$, or the following organic substrates: acetate $(20 \mathrm{mM})$, aspartate $(10 \mathrm{mM})$, glucose $(10$ $\mathrm{mM})$, glutamate $(10 \mathrm{mM})$, formate $(40 \mathrm{mM})$, pyruvate $(20 \mathrm{mM})$, raffinose $(10$ $\mathrm{mM})$, succinate $(10 \mathrm{mM})$, sucrose $(10 \mathrm{mM})$, sorbitol $(10 \mathrm{mM})$, xylose $(10 \mathrm{mM})$, and yeast extract $(0.05 \%)$. In order to determine whether the turbidity that developed resulted from contaminating heterotrophic bacteria, growth was monitored by determining viable cell counts on both solid medium $\mathrm{A}$ and solid medium $\mathrm{H}$

Formation of intermediate products. Formation of tetrathionate and trithio nate during growth on sodium thiosulfate and elemental sulfur was monitored by cyanolysis (16). Sulfate production was determined by measuring turbidity (using barium chloride precipitation) or by inductively coupled plasma atomic emission spectroscopy.

Anaerobic growth. Whether nitrate was used as an electron acceptor in the absence of oxygen was determined under autotrophic and heterotrophic conditions by using medium A supplemented with thiosulfate $(20 \mathrm{mM})$ or yeast extract $(0.05 \%)$. Medium A was supplemented with $33 \mathrm{mM} \mathrm{KNO}_{3}$ and $25 \mathrm{mM} \mathrm{NaHCO}_{3}$ Filled tubes were incubated at $50^{\circ} \mathrm{C}$ for 33 days when thiosulfate was used and for 15 days when yeast extract was used. Nitrate and nitrite concentrations were determined by the cadmium reduction method (6). Thiosulfate, tetrathionate and trithionate concentrations were determined by cyanolysis (16).

$G+C$ content and nature of the ubiquinone. Guanine-plus-cytosine $(G+C)$ contents were determined spectrophotometrically as described by Ulitzur (30) by using DNA from Escherichia coli ATCC 25922 as the standard. DNA was extracted by the method suggested by Beji et al. (1). Ubiquinone was extracted and identified as described by DiSpirito et al. (8).

Scanning electron microscopy and transmission electron microscopy. Thiobacillus thermosulfatus was grown on $\mathrm{S}^{0}$ tablets as described by Bryant et al. (4), and a scanning electron microscopy examination of glycocalyx production was performed as described by Blais et al. (2). The tablets were examined with a JEOL model JSM-T33OA scanning electron microscope. For transmission electron microscopy, thiobacillus cells grown on a solid medium $\mathrm{A}$ plate for $48 \mathrm{~h}$ at $50^{\circ} \mathrm{C}$ were removed by washing the plate with $2 \mathrm{ml}$ of $0.8 \% \mathrm{NaCl}$. The resulting suspension was centrifuged at $12,000 \times g$ for $10 \mathrm{~min}$. The pellet was washed three times with a $0.8 \% \mathrm{NaCl}$ solution and then treated for transmission electron microscopy. Thin layers were cut with a Reichert model OM V2 diamond microtome, placed on type $200 \mathrm{HH}$ copper grids, and stained with uranyl acetate and lead hydroxide. The grids were examined with a Philips model EM 300 electron microscope.

16S rRNA gene sequencing and analysis. DNA was extracted as described by Beji et al. (1). The $16 \mathrm{~S}$ rRNA gene was amplified by PCR. The primers used for DNA amplification were primers SSU 27 (3), SSU 536 (GTGCCAGCMGCCG CGGTAATAC), SSU 926 (AAACTYAAAKGAATTGACGG), and SSU 1195 (GAGGAAGGTGGGATGACGTC) for the $5^{\prime} \rightarrow 3^{\prime}$ DNA strand and primer SSU $1492^{\prime}(3)$ for the $3^{\prime} \rightarrow 5^{\prime}$ DNA strand. DNA amplification was performed with a Perkin-Elmer Cetus model 480 cycler. The temperature profile was as follows: initial denaturation at $94^{\circ} \mathrm{C}$ for $3 \mathrm{~min}$, followed by 30 cycles consisting of $94^{\circ} \mathrm{C}$ for $1 \mathrm{~min}, 53^{\circ} \mathrm{C}$ for $1 \mathrm{~min}$, and $73^{\circ} \mathrm{C}$ for $1.5 \mathrm{~min}$. The final extension step consisted of $73^{\circ} \mathrm{C}$ for $10 \mathrm{~min}$. The PCR products were purified by spin column chromatography (PCR purification kit; Qiagen, Chatworth, Calif.) and were sequenced directly by using an ABI model 373 automated sequencer and a Taq DyeDeoxy cycle sequencing kit (Perkin Elmer-ABI, Foster City, Calif.). The sequence which we obtained was aligned with 20 other 16S rRNA gene sequences (see Fig. 4 for taxon names) by using the PILEUP program of the University of Wisconsin Genetic Computer Group (7), and the alignment was completed manually. GenBank accession numbers for the other 16S rRNA sequences which we used were L01478, L01479, M34113, M79396 to M79398, M79401 to M79432, M90662, X07839, X75269, and Z29975. Desulfovibrio des. ulfuricans was used as an outgroup for rooting purposes. Ambiguous regions were removed, and the resulting alignment of 850 nucleotides (corresponding to positions 201 to 413,441 to 476,591 to 863 , and 1019 to 1339 of the $16 \mathrm{~S}$ rRNA gene of Thiobacillus thermosulfatus) was used for phylogenetic analyses.

A standard parsimony analysis was performed by using the branch-and-bound search algorithm of PAUP version 3.1 (29). Minimal gaps were considered missing values. One-parameter (12) and two-parameter (18) substitution rates, which also took into account transitions and transversions, were estimated from pairwise levels of sequence similarity by using MEGA, version $1.0(20)$. The pairwise sequence deletion option was used, and gaps were considered missing values. The resulting matrices of substitution rates were examined by the neighbor-joining method (23) by using MEGA. The confidence levels for nodes were estimated by a bootstrap procedure (10) in which we used 100 replicates for 
parsimony analyses (PAUP) and 500 replicates for neighbor-joining analyses (MEGA).

Nucleotide sequence accession number. The complete 16S rRNA gene sequence of Thiobacillus thermosulfatus has been deposited in the GenBank database under accession number U27839.

\section{RESULTS}

Isolation of Thiobacillus thermosulfatus. Initially, colonies on solid medium A were composed of Thiobacillus thermosulfatus and gram-positive sporeformers; the latter were subsequently identified as members of a thermophilic Bacillus species. After 10 subcultures on medium $\mathrm{A}$, the sporeformers disappeared. When a colony from a solid medium A culture was transferred to solid medium $\mathrm{H}$, no growth of the thiobacilli or sporeformers was observed after incubation for 15 days at $50^{\circ} \mathrm{C}$. Thus, the heterotrophic sporeformers were eliminated from the Thiobacillus thermosulfatus colonies on medium A. Other gelling agents were used with medium A supplemented with thiosulfate. Only $2 \%$ purified agar (BBL) gave results similar to the results obtained with Gelrite. With $2 \%$ Bacto Agar (Difco), growth was slower than the growth obtained with Gelrite, and it took more than 8 days to detect acid production when it was detected at all. The relationship between dilutions on Bacto Agar and colony counts was also poor. Neither growth nor acid production was observed on medium containing $1 \%$ agarose (Sigma) after incubation for 15 days.

Growth conditions. A decrease in the viable cell counts on solid medium A occurred after $5 \mathrm{~h}$ if the $\mathrm{pH}$ was less than 3.6. At $\mathrm{pH} 4.4,5.0,6.8$, and 7.8, the amount of biomass increased slightly; at these $\mathrm{pH}$ values, growth was observed only when the plate count method was used. At $\mathrm{pH} 5.8$ and 6.5, growth was observed by the turbidity and plate count methods. During $\mathrm{pH}$-controlled experiments, the maximum specific growth rate was obtained at $\mathrm{pH}$ values between $5.2\left(0.180 \mathrm{~h}^{-1}\right)$ and 5.6 $\left(0.182 \mathrm{~h}^{-1}\right)$ and at temperatures between $50.0^{\circ} \mathrm{C}\left(0.180 \mathrm{~h}^{-1}\right)$ and $52.5^{\circ} \mathrm{C}\left(0.173 \mathrm{~h}^{-1}\right)$. Growth occurred on media containing thiosulfate, tetrathionate, and elemental sulfur. Growth did not occur on medium containing thiocyanate under the conditions tested. During growth on thiosulfate, tetrathionate, trithionate, and sulfate were produced (Fig. 1). Heterotrophic growth occurred on media containing yeast extract, glutamate, and succinate. Characteristic odor was noticed at the end of growth on organic and inorganic substrates; this odor may have been due to the excretion of organic compounds, as has been shown for Thiobacillus aquaesulis (35). Under anaerobic conditions, no growth occurred under autotrophic and heterotrophic conditions. Tetrathionate and trithionate were not produced from thiosulfate, and the $\mathrm{pH}$ remained stable. Under both autotrophic and heterotrophic conditions, no nitrite resulting from reduction of nitrate was observed.

Microscopy. An electron micrograph (Fig. 2) revealed that a single polar flagellum, polyhedral bodies, and polyphosphate inclusions were present in each cell. Scanning electron microscopy (Fig. 3) revealed that an extensive glycocalyx was produced during growth on $S^{0}$ tablets. The filamentous appearance of the glycocalyx was probably the result of the dehydration procedure used during sample preparation (28). Cells intimately associated with the glycocalyx can be seen in Fig. 3. Typically, two or three polyphosphate inclusions per cell were visible when Loeffler's staining procedure was used. The dimensions of the cells during exponential growth were 1.3 to 2.3 by $0.9 \mu \mathrm{m}$. There were two cells per chain, and the Gram reaction was negative.

$\mathbf{G}+\mathbf{C}$ and ubiquinone contents. The average $\mathrm{G}+\mathrm{C}$ content was $61 \pm 1 \mathrm{~mol} \%$. The ratio of optical density at $260 \mathrm{~nm}$ to optical density at $280 \mathrm{~nm}$ was more than 1.76 in all cases,

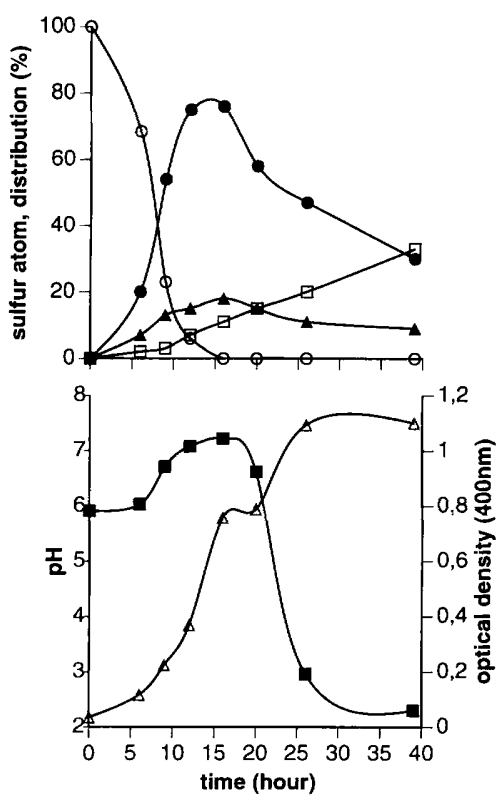

FIG. 1. Evolution of intermediate products during growth on thiosulfate. Symbols: $O$, thiosulfate; $\boldsymbol{\theta}$, tetrathionate; $\Delta$, trithionate; $\square$, sulfate; $\triangle$, optical density; $\mathbf{\square}, \mathrm{pH}$. The arrested growth observed between 15 and $20 \mathrm{~h}$ was the result of weak growth caused by an increase in the $\mathrm{pH}$ or transition from the use of thiosulfate to the use of tertathionate (diauxi). At the end of the experiment, nearly $30 \%$ of the initial sulfur was missing; we suspect that this sulfur was transformed to elemental sulfur since a white precipitate was observed. Accumulation of tetrathionate and trithionate was probably a result of growth inhibition caused by the final acidic conditions.

indicating that the samples which we used were clean. The $R_{f}$ values for ubiquinone Q8 (extracted from Escherichia coli) and ubiquinone Q10 were 0.86 and 0.69 , respectively. The $R_{f}$ value for the ubiquinone extracted from Thiobacillus thermosulfatus was 0.87 , and this ubiquinone was formally identified as ubiquinone Q8. Addition of ubiquinone Q10 to a Thiobacillus thermosulfatus extraction preparation resulted in two different spots with $R_{f}$ values of 0.86 and 0.70 , corresponding to ubiquinones Q8 and Q10, respectively.

Phylogenetic analysis. The topologies estimated from the standard parsimony analysis and the neighbor-joining analyses of one-parameter and two-parameter substitution rates were essentially the same. The two neighbor-joining trees were identical and differences with the most parsimonious tree were observed only for the nodes that were not supported by bootstrap estimates of $50 \%$ or more, which are shown as polytomies on the neighbor-joining tree derived from the analysis of oneparameter substitution rates (Fig. 4); this tree summarizes the phylogenetic relationships among the Thiobacillus species, including the relationships based on the recently determined $16 \mathrm{~S}$ rRNA gene sequences of Thiobacillus caldus, Thiobacillus hydrothermalis, Thiobacillus thermosulfatus, and Thiobacillus ferrooxidans B-S3. The $16 \mathrm{~S}$ rRNA gene sequence of thiobacillus strain NF13 (GenBank accession numbers M79387, M79388, and M79389) was intentionally omitted from the phylogenetic analyses because only 456 nucleotides of this sequence have been determined and only 249 of these 456 nucleotides could be used in the final alignment; thus, the number of sites available for a balanced analysis of all other taxa would have been reduced, and this would have decreased the precision of the estimated trees. Nevertheless, when such an analysis was performed, strain NF13 occurred with Thiomicrospira thyasirae (previously named Thiobacillus thyasiris) with a neighbor-join- 


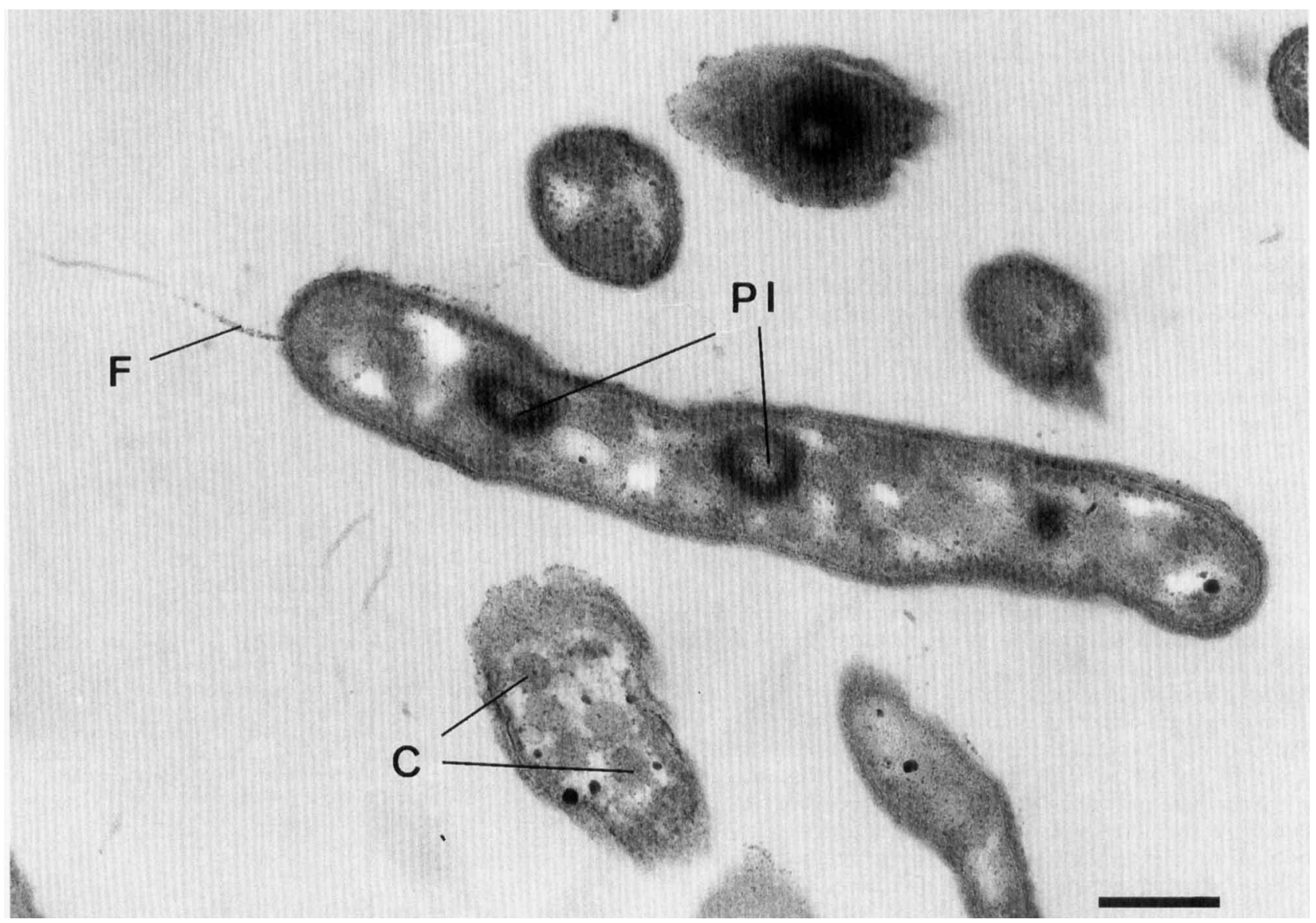

FIG. 2. Transmission electron micrograph of Thiobacillus thermosulfatus. F, flagellum; C, polyhedral bodies; PI, polyphosphate inclusions. Bar $=0.2 \mu \mathrm{m}$. Magnification, $\times 63,200$.

ing bootstrap value of $58 \%$. It follows that thiobacillus strain NF13 should not be considered a Thiobacillus species.

The newly isolated organism, Thiobacillus thermosulfatus, was placed in the beta subdivision and beta- 1 subgroup of the Proteobacteria because of its relationship with Thiobacillus perometabolis, which was previously placed in this subgroup (21). In fact, the highest level of sequence similarity for Thiobacillus thermosulfatus was the level of sequence similarity obtained with Thiobacillus perometabolis $(96.5 \%$, obtained from the sequence alignment used to infer phylogenetic trees) (Table 1). When we took into account all of the sequence information available for Thiobacillus thermosulfatus and Thiobacillus perometabolis, including the information for regions deleted from the phylogenetic analyses because of alignment ambiguities between remote taxa, the level of similarity was $95.4 \%$. We obtained low levels of sequence similarity between Thiobacillus thermosulfatus and the two other thermophilic thiobacilli, Thiobacillus caldus $(80.2 \%)$ and Thiobacillus tepidarius $(80.9 \%)$. Our phylogenetic analysis also revealed that the moderately themophilic acidophilic organism Thiobacillus caldus is closely related to Thiobacillus ferrooxidans LM2, a facultative thermophile. The strictly autotrophic mesophilic organism Thiobacillus hydrothermalis was found to be closely related to Thiobacillus neapolitanus, which is also a strictly autotrophic mesophilic organism. The newly sequenced organism Thiobacillus thiooxidans B-S3 belonged to the beta subdivision and was closely related to the cluster containing almost all of the Thiobacillus ferrooxidans and Thiobacillus thiooxidans strains, as recently shown by Goebel and Stackebrandt (11). As found in previous studies $(11,21)$, our phylogenetic tree confirmed that the genus Thiobacillus is heterogeneous and polyphyletic and thus is not a natural group.

\section{DISCUSSION}

The newly isolated organism Thiobacillus thermosulfatus is phenotypically quite different from all of the other Thiobacillus species that have been isolated except the thiobacillus described by Williams and Hoare (32). The isolate of Williams and Hoare had optimum $\mathrm{pH}$ and temperature values similar to those of Thiobacillus thermosulfatus and was able to produce enough sulfuric acid from thiosulfate to increase the level of acidity to approximately $\mathrm{pH} 2.6$, like Thiobacillus thermosulfatus. The only difference between these two organisms was the difference in their $\mathrm{G}+\mathrm{C}$ contents $(66 \mathrm{~mol} \%$ for strain of Williams and Hoare, compared with $61 \mathrm{~mol} \%$ for Thiobacillus thermosulfatus). Unfortunately, the isolate of Williams and Hoare has not been deposited in any type culture collection, and so additional comparisons could not be performed. Thiobacillus tepidarius and Thiobacillus aquaesulis are also phenotypically similar to Thiobacillus thermosulfatus. While Thiobacillus thermosulfatus has an optimum temperature $\left(50\right.$ to $\left.52^{\circ} \mathrm{C}\right)$ that is different from the optimum temperatures of Thiobacillus tepidarius and Thiobacillus aquaesulis $\left(43\right.$ to $45^{\circ} \mathrm{C}$ and around $43^{\circ} \mathrm{C}$, respectively $\left.[33,35]\right)$, Thiobacillus thermosulfatus is facultatively chemolithoautotrophic on yeast extract, like 


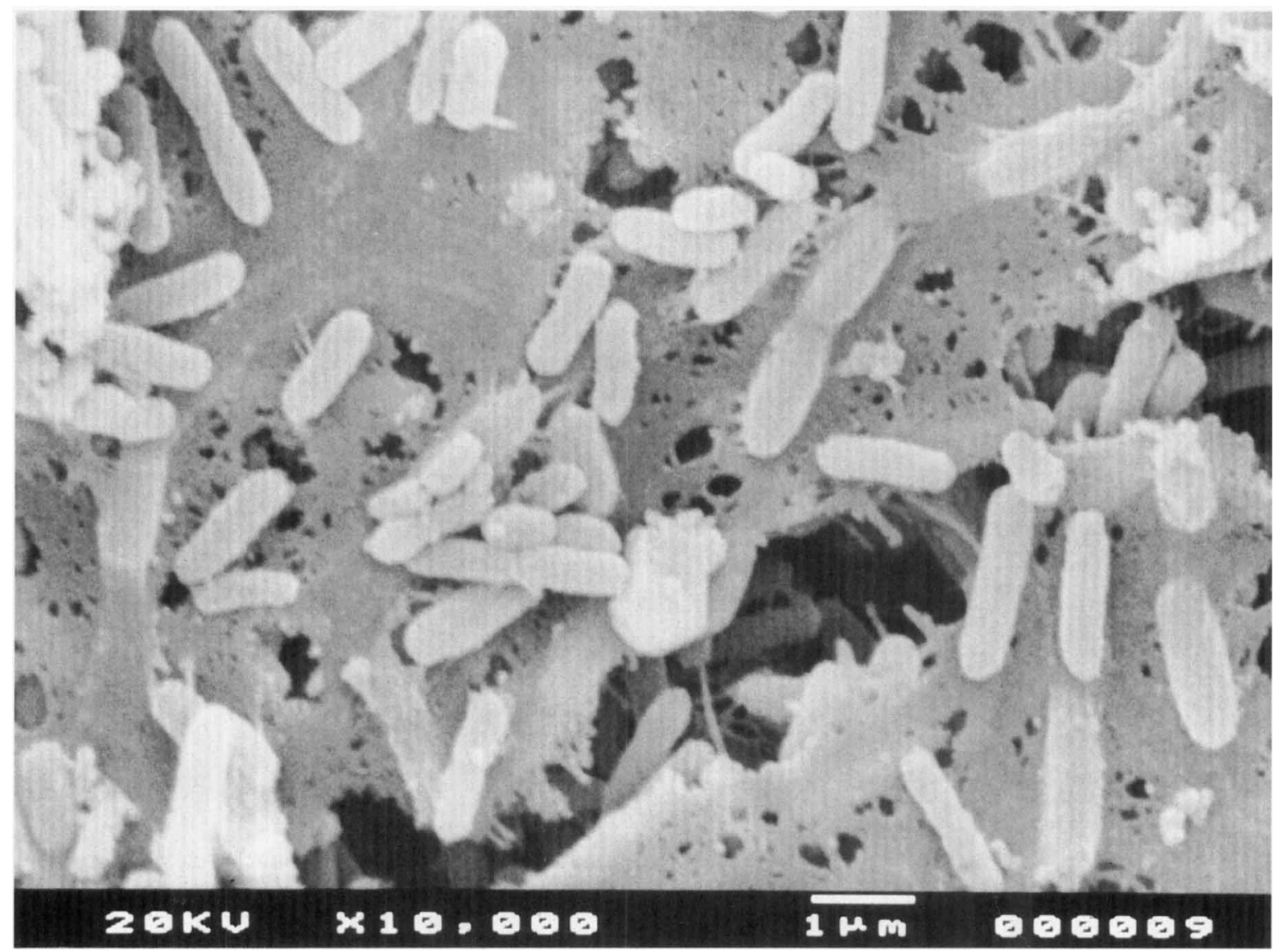

FIG. 3. Scanning electron micrograph of glycocalyx production during growth on elemental sulfur.

Thiobacillus aquaesulis, but it can also grow on glutamate and succinate. The optimum $\mathrm{pH}$ for Thiobacillus tepidarius is 6.0 to 7.5 , and the optimum $\mathrm{pH}$ for Thiobacillus aquaesulis is around 7.6, whereas the optimum $\mathrm{pH}$ for Thiobacillus thermosulfatus is between 5.2 and 5.6. The $\mathrm{G}+\mathrm{C}$ content of Thiobacillus thermosulfatus ( $61 \mathrm{~mol} \%$ ) is slightly different from the $\mathrm{G}+\mathrm{C}$ contents of Thiobacillus tepidarius (66.6 mol\%) and Thiobacillus aquaesulis $(65.7 \mathrm{~mol} \%)$. Autotrophic growth of Thiobacillus thermosulfatus under optimum conditions decreased the $\mathrm{pH}$ from neutrality to around 2.5 , a phenomenon which was not observed during growth of Thiobacillus tepidarius and Thiobacillus aquaesulis under optimum conditions. Thiobacillus thermosulfatus does not appear to be phenotypically related to the genus Thermothrix (5) because of its inability to denitrify and grow under anaerobic conditions.

The results of phylogenetic analyses of $16 \mathrm{~S}$ rRNA gene sequences indicated that Thiobacillus thermosulfatus is related to Thiobacillus perometabolis and Thiobacillus thioparus, which is the type species of the genus Thiobacillus (17). However, the levels of 16S rRNA sequence similarity between Thiobacillus thermosulfatus and these organisms are less than the limit (97\%) used to define distinct species at the DNA level without the requirement for DNA-DNA reassociation tests (26). Furthermore, Thiobacillus thermosulfatus is phenotypically quite different from these strains. It cannot denitrify and grow under anaerobic conditions and is not a mesophilic obligate autotroph like Thiobacillus thioparus (19). Thiobacillus thermosulfatus has an optimum growth temperature $\left(50\right.$ to $\left.52^{\circ} \mathrm{C}\right)$ that is greater than the maximum growth temperature for Thioba- cillus perometabolis $\left(42^{\circ} \mathrm{C}\right)(14,15)$. The $\mathrm{G}+\mathrm{C}$ content of Thiobacillus thermosulfatus $(61 \mathrm{~mol} \%)$ is also different from the $\mathrm{G}+\mathrm{C}$ content of Thiobacillus perometabolis $(65 \mathrm{~mol} \%)$. In addition, heterotrophic growth of Thiobacillus perometabolis on glutamate and succinate begins after a long lag phase (about 2 weeks) (15), which was not observed during heterotrophic growth of Thiobacillus thermosulfatus on these substrates. Because Thiobacillus thermosulfatus has at least two differentiating phenotypic characteristics and a divergent 16S rRNA sequence, it can be considered a new species $(26,31)$.

We believe that reassociation experiments involving Thiobacillus thermosulfatus and Thiobacillus peromatabolis DNAs were not necessary because the level of $16 \mathrm{~S}$ rRNA sequence similarity (95.4\%) was below the critical value of $97 \%$ (26). Indeed, according to Stackebrandt and Geobel (26), "organisms that have less than $97.0 \%$ sequence homology will not reassociate to more than $60 \%$, no matter which hybridization method is applied." The phylogenetic position of Thiobacillus thermosulfatus, together with the reclassification of Thiobacillus versutus and Thiobacillus thyasiris as Paracoccus versutus (13) and Thiomicrospira thyasirae $(9,36)$, respectively, and the close relationship between Thiobacillus acidophilus and the genus Acidiphilium suggest that the genus Thiobacillus is more restricted than previously thought; most Thiobacillus strains belong to the beta subdivision of the Proteobacteria.

From an ecological point of view, bioproduction of sulfate at $50^{\circ} \mathrm{C}$ in the presence of elemental sulfur was observed not only in sludge samples obtained from municipal wastewater treatment plants but also in soil samples and sludge samples ob- 


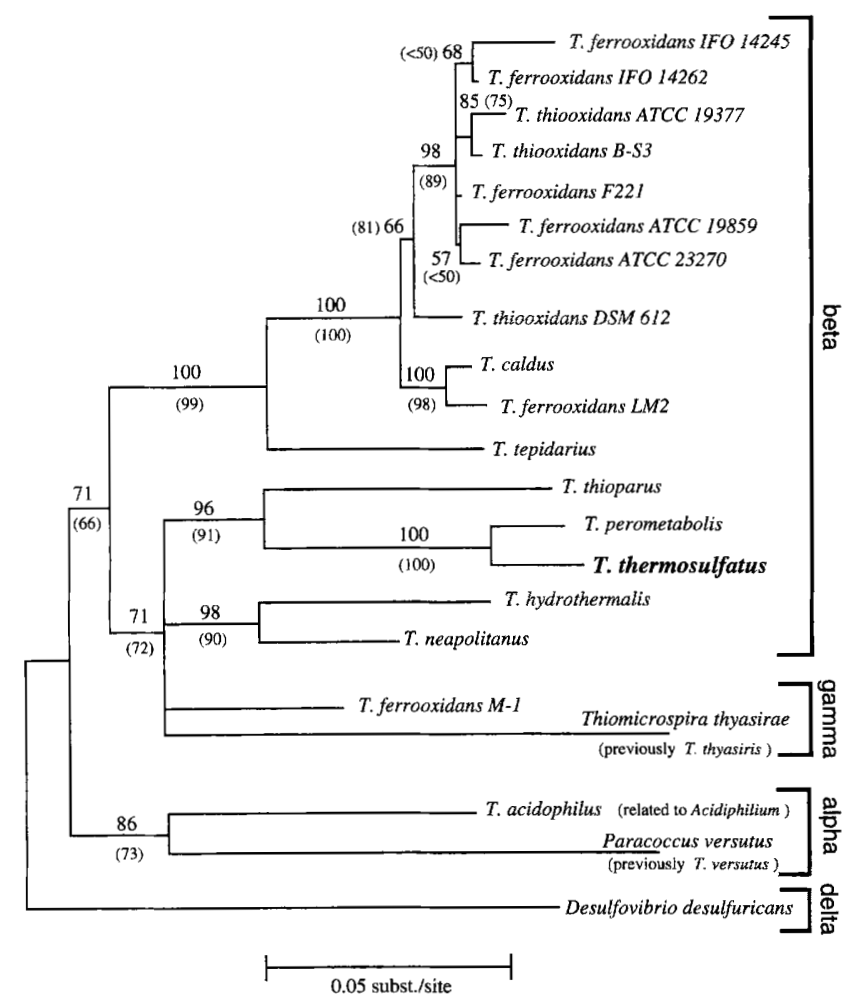

FIG. 4. Phylogenetic relationships among Thiobacillus species and position of Thiobacillus thermosulfatus on the basis of the results of a neighbor-joining analysis of one-parameter rates of nucleotide substitution derived from the $16 \mathrm{~S}$ rRNA gene sequence. The tree topology was identical to the topology obtained from a standard parsimony analysis and the topology obtained from a neighborjoining analysis of two-parameter rates of substitution. The numbers on the branches not in parentheses are bootstrap values obtained from 500 replicates (neighbor joining). The numbers in parentheses are bootstrap values obtained by parsimony analysis (100 replicates). Only nodes supported by bootstrap values greater than $50 \%$ are shown. Alpha, beta, delta, and gamma are subdivisions of the Proteobacteria. subst., substitution.

tained from the pulp and paper industry (data not shown). We postulate that Thiobacillus thermosulfatus or a similar organism is responsible for this activity and is probably ubiquitous. The use of Gelrite as a gelling agent was probably the main factor responsible for the successful isolation of Thiobacillus thermosulfatus in this study.

Because the organism described in this paper is a rodshaped eubacterium that obtains energy for autotrophic growth by oxidizing inorganic sulfur substrates and because it is phenotypically and phylogenetically distinct from other thiobacilli, this isolate is formally described below as a new species of the genus Thiobacillus.

Description of Thiobacillus thermosulfatus sp. nov. The description of Thiobacillus thermosulfatus (ther. mo. sul. fa' tus. Gr. n. thermus, heat; L. n. sulfatus, sulfur; L. adj. thermosulfa$t u s$, organism that produces sulfate and grows at high temperatures) below is based on the type strain, which has been deposited in the American Type Culture Collection as strain ATCC 51520. Cells are gram negative, motile by means of a single polar flagellum, and rod shaped ( 1.3 to 2.3 by $0.9 \mu \mathrm{m}$ ). The cells contain polyphosphate inclusions (typically two or three inclusions) and polyhedral bodies. Colonies on autotrophic solid medium (medium A) are round and small (diameter, $<1 \mathrm{~mm}$ ); they are translucent or have sulfur deposits in the center. Thiobacillus thermosulfatus is strictly aerobic and grows autotrophically on thiosulfate, tetrathionate, and sulfur and heterotrophically on yeast extract, succinate, and glutamate. Thiobacillus thermosulfatus does not grow on carbohydrates, pyruvate, acetate, or formate. When thiosulfate is used as the primary energy source, tetrathionate, trithionate, and sulfate are produced. During growth on elemental sulfur and thiosulfate, the $\mathrm{pH}$ decreases from neutrality to around $\mathrm{pH} 2.5$. During elemental sulfur oxidation, a considerable amount of sulfate (up to $6,000 \mathrm{mg} / \mathrm{liter}$ ) is produced, depending on the $\mathrm{pH}$ buffering capacity of the medium. The cells adhere to elemental sulfur by means of a glycocalyx, as judged by the extensive production of a glycocalyx during growth on this substrate. Autotrophic growth on thiosulfate occurs between $\mathrm{pH} 4.3$ and 7.8 and at temperatures of 34 to $65^{\circ} \mathrm{C}$; optimum growth occurs at $\mathrm{pH} 5.2$ to 5.6 and 50 to $52.5^{\circ} \mathrm{C}$. Ubiquinone Q8 is present in the respiratory chain. The $\mathrm{G}+\mathrm{C}$ content of the DNA is $61 \pm 1 \mathrm{~mol} \%$. No denitrification occurs under autotrophic and heterotrophic conditions. As determined by a $16 \mathrm{~S}$ rRNA gene sequence analysis, Thiobacillus thermosulfatus belongs to the beta subdivision of the Proteobacteria and is closely related phylogenetically to Thiobacillus perometabolis and Thiobacillus thioparus. Its 16S rRNA sequence is most similar to the 16S rRNA sequence of Thiobacillus perometabolis (level of similarity, 95.4\%). The GenBank accession number for the complete 16S rRNA gene sequence of Thiobacillus thermosulfatus is U27839.

\section{ACKNOWLEDGMENTS}

We thank D. P. Kelly, R. Guay, J.-C. Auclair, and T. R. Sreekrishnan for reading a draft of the manuscript and providing useful suggestions. We also thank J.-F. Blais for suggestions during the bacterial isolation procedure, E. Emond for the early tentative sequencing and help during PCR amplification, L. Simon and J. Renaud for assistance with automated gene sequencing, and A. Roy for help with the phylogenetic analyses.

We thank Fonds pour la Formation de Chercheurs et l'Aide à la Recherche of Québec and the Natural Sciences and Engineering Research Council of Canada (grants A9484, STR 0100710, and STR 149770) for supporting this research.

\section{REFERENCES}

1. Beji, A., D. Izard, F. Gavini, H. Leclerc, M. Leseine-Delstanche, and J. Krembel. 1987. A rapid chemical procedure for isolation and purification of chromosomal DNA from Gram-negative bacilli. Anal. Biochem. 162:18-23.

2. Blais, J.-F., R. D. Tyagi, N. Meunier, and J. C. Auclair. 1994. The production of extracellular appendages during bacterial colonization of elemental sulphur. Process Biochem. 29:475-482.

3. Bousquet, J., L. Simon, and M. Lalonde. 1990. DNA amplification from vegetative and sexual tissues of trees using polymerase chain reaction. Can. J. For. Res. 20:254-257.

4. Bryant, R. D., J. W. Costerton, and E. J. Laishley. 1984. The role of Thiobacillus albertis glycocalyx in the adhesion of cells to elemental sulfur. Can. J. Microbiol. 30:81-90.

5. Caldwell, D. E., S. J. Caldwell, and J. P. Laycock. 1976. Thermothrix thiopanis gen. et sp. nov., a facultatively anaerobic facultative chemolithotroph living at neutral $\mathrm{pH}$ and high temperature. Can. J. Microbiol. 22:1509-1517.

6. Clesceri, L. S., A. E. Greenberg, and R. R. Trussell. 1989. Standard methods for the examination of water and wastewater, 17th ed. American Public Health Association, Washington, D.C.

7. Devereux, J. P., P. Haeberli, and O. Smithies. 1984. A comprehensive set of sequence analysis programs for the VAX. Nucleic Acids Res. 12:387-395.

8. DiSpirito, A. A., W. H.-T. Lho, and O. H. Tuovinen. 1983. A novel method for the isolation of bacterial quinones and its application to appraise the ubiquinone composition of Thiobacillus ferrooxidans. Arch. Microbiol. 135: $77-80$.

9. Distel, D. L., and A. P. Wood. 1992. Characterization of the gill symbiont of Tyasira flexuosa (Thyasiridae: Bivalvia) by use of polymerase chain reaction and 16S rRNA sequence analysis. J. Bacteriol. 174:6317-6320.

10. Felsenstein, J. 1985. Confidence limits on phylogenies: an approach using the bootstrap. Evolution 39:783-791.

11. Goebel, B. M., and E. Stackebrandt. 1994. Cultural and phylogenetic analysis of mixed microbial populations found in natural and commercial bioleaching environments. Appl. Environ. Microbiol. 60:1614-1621. 
12. Jukes, T. H., and C. R. Cantor. 1967. Evolution of protein molecules, p. 21-132. In H. N. Munro (ed.), Mammalian protein metabolism. Academic Press, New York.

13. Katayama, Y., A. Hiraishi, and H. Kuraishi. 1995. Paracoccus thiocyanatus sp. nov., a new species of thiocyanate-utilizing facultative chemolithotroph, and transfer of Thiobacillus versutus to the genus Paracoccus as Paracoccus versutus comb. nov, with emendation of the genus. Microbiology 141:14691477.

14. Katayama-Fujimura, Y., I. Kawashima, N. Tsuzaki, and H. Kuraishi. 1984 Physiological characteristics of the facultatively chemolithotrophic Thiobacillus species Thiobacillus delicatus nom. rev., emend., Thiobacillus perometabolis, and Thiobacillus intermedius. Int. J. Syst. Bacteriol. 34:139-144.

15. Katayama-Fujimura, Y., and H. Kuraishi. 1983. Emendation of Thiobacillus perometabolis London and Rittenberg 1967. Int. J. Syst. Bacteriol. 33:650651.

16. Kelly, D. P., L. A. Chambers, and P. A. Trudinger. 1969. Cyanolysis and spectrophotometric estimation of trithionate in mixture with thiosulfate and tetrathionate. Anal. Chem. 41:898-901.

17. Kelly, D. P., and A. P. Harrison. 1984. Genus Thiobacillus, p. 1842-1858. In J. T. Staley, M. P. Bryant, N. Pfennig, and J. G. Holt (ed.), Bergey's manual of systematic bacteriology, vol. 3. The Williams \& Wilkins Co., Baltimore.

18. Kimura, M. 1980. A simple method for estimating evolutionary rate of base substitutions through comparative studies of nucleotide sequences. J. Mol. Evol. 16:111-120.

19. Kuenen, J. G., L. A. Robertson, and O. H. Tuovinen. 1992. The genera Thiobacillus, Thiomicrospora, and Thiosphaera, p. 2638-2657. In A. Balows, H. G. Truper, M. Dworkin, W. Harder, and K. H. Schleifer (ed.), The prokaryotes, 2nd ed. Springer-Verlag, New York.

20. Kumar, S., K. Tamura, and M. Nei. 1993. MEGA: molecular evolutionary genetics analysis, version 1.0. The Pennsylvania State University, University Park.

21. Lane, D. J., A. P. Harisson, Jr., D. Stahl, B. Pace, S. J. Giovannoni, G. J. Olsen, and N. R. Pace. 1992. Evolutionary relationships among sulfur- and iron-oxidizing eubacteria. J. Bacteriol. 174:268-278.

22. Lin, C. C., and L. E. Casida, Jr. 1984. Gelrite as a gelling agent in media for growth of thermophilic microorganisms. Appl. Environ. Microbiol. 47:427-429.

23. Saitou, N., and M. Nei. 1987. The neighbor-joining method: a new method for reconstructing phylogenetic trees. Mol. Biol. Evol. 4:406-425.

24. Shooner, F., and R. D. Tyagi. Microbial ecology of simultaneous thermophilic microbial leaching and digestion of sewage sludge. Can. J. Microbiol., in press.

25. Shooner, F., and R. D. Tyagi. Thermophilic microbial leaching of heavy metals from municipal sludge using indigenous sulfur-oxidizing microbiota. Appl. Microbiol. Biotechnol., in press.

26. Stackebrandt, E., and B. M. Goebel. 1994. Taxonomic note: a place for DNA-DNA reassociation and 16S rRNA sequence analysis in the present species definition in bacteriology. Int. J. Syst. Bacteriol. 44:846-849.

27. Stackebrandt, E., R. G. E. Murray, and H. G. Trüper. 1988. Proteobacteria classis nov., a name for the phylogenetic taxon that includes the purple bacteria and their relatives. Int. J. Syst. Bacteriol. 38:321-325.

28. Sutherland, I. W. 1972. Bacterial exopolysaccharides. Adv. Microb. Physiol. 8:143-213.

29. Swofford, D. L. 1993. PAUP-phylogenetic analysis using parsimony, version 3.1. Illinois Natural History Survey, Champaign.

30. Ulitzur, S. 1972. Rapid determination of DNA base composition by ultraviolet spectroscopy. Biochim. Biophys. Acta 272:1-11.

31. Ursing, J. B., R. A. Rossello-Mora, E. García-Valdés, and J. Lalucat. 1995. Taxonomic note: a pragmatic approach to the nomenclature of phenotypically similar genomic groups. Int. J. Syst. Bacteriol. 45:604.

32. Williams, R. A. D., and D. S. Hoare. 1972. Physiology of a new facultatively autotrophic thermophilic thiobacillus. J. Gen. Microbiol. 70:555-566.

33. Wood, A. P., and D. P. Kelly. 1985. Physiological characteristics of a new thermophilic obligately chemolithotrophic Thiobacillus species, Thiobacillus tepidarius. Int. J. Syst. Bacteriol. 35:434-437.

34. Wood, A. P., and D. P. Kelly. 1986. Chemolithotrophic metabolism of the newly-isolated moderately thermophilic, obligately autotrophic Thiobacillus tepidarius. Arch. Microbiol. 144:71-77.

35. Wood, A. P., and D. P. Kelly. 1988. Isolation and physiological characterisation of Thiobacillus aquaesulis sp. nov., a novel facultatively autotrophic moderate thermophile. Arch. Microbiol. 149:339-343.

36. Wood, A. P., and D. P. Kelly. 1993. Reclassification of Thiobacillus thyasiris as Thiomicrospora thyasirae comb. nov., an organism exhibiting pleomorphism in response to environmental conditions. Arch. Microbiol. 159:45-47. 